\title{
SURVEY OF THE OPINIONS ON THE OCCUPATIONAL HEALTH SYSTEM IN TURKEY EXPRESSED BY PATIENTS OF THE ISTANBUL HOSPITAL OF OCCUPATIONAL DISEASES
}

\author{
INCI HOT ${ }^{1}$, ESIN KARLIKAYA ${ }^{2}$, and MEHMET SARPER ERDOGAN ${ }^{3}$ \\ ${ }^{1}$ Istanbul University, Istanbul, Turkey \\ Cerrahpasa Medical Faculty, Department of Ethics \\ ${ }^{2}$ Trakya University, Edirne, Turkey \\ Medical School, Department of Ethics \\ ${ }^{3}$ Istanbul University, Istanbul, Turkey \\ Cerrahpasa Medical Faculty, Department of Public Health
}

\begin{abstract}
Objective: To examine the opinion of patients of an occupational diseases hospital on the quality of provision of occupational medicine services in Turkey. Materials and Methods: A total of 189 patients were interviewed using a 13-item survey about their jobs and workplaces. Results: The overall results of this study were as follows: $80.4 \%$ of the patients stated that physicians were located at their workplaces; $66.1 \%$ stated that inadequate attention was given to ensure the physical, psychological and social health of the employees; and $63.5 \%$ stated that sufficient protection against health risks was not provided. Conclusions: The quality of provision of occupational medicine services should be improved.
\end{abstract}

Key words:

Workplace physician, Occupational disease, Occupational diseases hospitals, Patient's rights and ethics

\section{INTRODUCTION}

Occupational diseases are temporary or permanent disorders or conditions caused by risk factors emanating from the workplace [1]. Employees in Turkey are categorized as either white-collar or blue-collar and are subjected to different laws depending on their individual rights. Blue-collar workers, mostly working in industrial environments with high risks, must be insured by the Social Security Institution. Compensation benefits for workers with occupational diseases are provided only for this group. When an employer suspects that a worker has an occupational disease and reports this to the Regional Labor Directorate, procedures begin for legal compensation benefits [2]. First, the worker is referred to a State Hospital. Having been treated there, the worker is referred to an Occupational Disease Hospital run by the state, if doctors think that the disease has occupational background. The final decision

Received: July 1, 2010. Accepted: November 26, 2010.

Address reprint request to I. Hot, Istanbul University, Cerrahpasa Tıp Fakültesi, Temel Bilimler Tıp Etiği Anabilim Dalı 34098 Aksaray Istanbul, Turkey (e-mail: incihot@istanbul.edu.tr). 
on whether the disease is occupational is taken by the doctors of the Occupational Diseases Hospital. The findings of physical and laboratory examination are brought to doctors council of the hospital by the treating physician and then the decision is made basing on the findings [3].

In Turkey, the Law of General Public Health, enacted in 1930 and still in force, requires the employment of workplace physicians [4]. Furthermore, Labor Law, No. 4857, effective in 2003, outlined the principles of occupational health and safety and provided a regulation with detailed information pertaining to workplace physicians and their working conditions. According to this law, healthcare at the workplace is a service provided at different intervals according to the number of workers at companies with more than 50 employees [5]. All physicians in Turkey are allowed to act as workplace physicians if they have been operating as inspectors for the Ministry of Labor for more than three years, or if they have graduated from a postgraduate education program in occupational medicine, or if they have completed a certificate training program for workplace physicians [6]. Internists who have completed threeyear post-graduate studies are also entitled to a speciality in occupational diseases. The number of occupational health specialists is remarkably low [7].

There are three hospitals of occupational diseases in Turkey located in Ankara, Istanbul and Zonguldak. This survey was conducted at the Istanbul Hospital of Occupational Diseases. The Istanbul hospital has the capacity to treat 52 inpatients per day, with 37429 outpatients and 682 inpatients treated in 2007.

By definition, occupational health is the promotion and maintenance of the physical, mental and social health of workers to the highest degree in all occupations. Providing the healthiest and most humane conditions at workplaces is requisite for labor and labor health ethics [8,9]. Moreover, the importance of employee health and respect for human rights, particularly the right to life, are synonymous [10,11].

Nowadays, it is not enough to merely treat or compensate employees for occupational accidents or diseases whose results have threatening social and economic impact. Therefore, the first priority should be the improvement of working conditions [11,12].

The aim of this study is to examine the opinion of patients of an occupational diseases hospital on the quality of provision of occupational medicine services in Turkey.

\section{MATERIALS AND METHODS}

Prior to conducting the study, acknowledgement of the regional ethics board and the hospital's permission were both obtained. The sampling group of the study would compose of all patients who had been hospitalized in the Istanbul Hospital of Occupational Diseases during a three-month period. The inclusive criteria for the collective was being treated as an inpatient at any time in that period. The 13-item survey was administered to 189 hospitalized patients, following their informed consent, who were hospitalized in the Istanbul Hospital of Occupational Diseases at least for one day between $14 \mathrm{Ju}$ ly 2008 and 12 October 2008. The survey concentrated on questions related to patient's rights and healthcare services at hospitals of occupational diseases. Patients answered the questions using a three-point Likert scale ( 1 = yes, 2 = undecided, $3=$ no).

The numerical variables of the study included age, duration of employment, the number of employees at the workplace, and the duration of hospital stays; the categorical variables included sex, education, sector, city, presence of workplace physicians, and the duration of hospital stays. The numerical variables when comparing more than two groups were tested by the Kruskal-Wallis Variance Analysis. The categorical variables were analyzed with the Pearson Chi Square test. SPSS 16.0 was used for data analyses. 


\section{RESULTS}

Out of the 189 patients $(\mathrm{n}=187$ ) surveyed, $99 \%$ of the workers were male; $42.3 \%(n=80)$ had graduated from primary school; $12.7 \%(n=24)$, from secondary school; $38 \%(n=73)$, from high school; $6.4 \%(\mathrm{n}=12)$, from an academy or college. The patients working in Istanbul made up $40.7 \%$, while the remainder were mainly from Kocaeli and Bursa. The following table shows the distribution of patients who participated in the survey according to the sector.

Out of those surveyed, $64.6 \%(n=122)$ had been treated for intoxication; $21.7 \%(\mathrm{n}=41)$, for restrictive lung disease; $7.4 \%(\mathrm{n}=14)$, for obstructive lung disease; and $6.3 \%(\mathrm{n}=12)$, for muscle and joint diseases.

While $29.6 \%$ of the patients $(\mathrm{n}=56)$ stated that they had previously been hospitalized in occupational diseases hospitals, $42.9 \%(n=24)$ had been hospitalized for the second time in the same hospital; $23.2 \%(\mathrm{n}=13)$, for the third time; $16.1 \%(\mathrm{n}=9)$, for the fourth time; and $10.7 \%$ $(n=6)$, for the fifth time.
Table 1. Distribution of participants by sector

\begin{tabular}{lrc}
\hline \multirow{2}{*}{ Sector } & \multicolumn{2}{c}{ Distribution } \\
\cline { 2 - 3 } & $\mathrm{n}$ & $\%$ \\
\hline Manufacturing (machines) & 61 & 32.3 \\
Petro-Chemical & 49 & 25.9 \\
Textiles & 31 & 16.4 \\
Shipyards & 21 & 11.1 \\
Manufacturing (vehicles) & 13 & 6.9 \\
Glass industry & 6 & 3.2 \\
Leather industry & 4 & 2.9 \\
Mining & 2 & 1.1 \\
Typography & 2 & 1.1 \\
Total & 189 & 100.0 \\
\hline
\end{tabular}

Moreover, $45 \%(\mathrm{n}=85)$ of the patients stated that they had not been placed in jobs suitable to their individual requirements at the workplace.

The participants' opinions on the practice of patients rights during treatment at the occupational disease hospital are given in the following table.

Table 2. Participants' opinions on patient rights practised during hospital treatment

\begin{tabular}{|c|c|c|c|c|c|c|}
\hline \multirow{2}{*}{ Opinions } & \multicolumn{2}{|c|}{ Yes } & \multicolumn{2}{|c|}{ No } & \multicolumn{2}{|c|}{ Undecided } \\
\hline & $\mathrm{n}$ & $\%$ & $\mathrm{n}$ & $\%$ & $\mathrm{n}$ & $\%$ \\
\hline $\begin{array}{l}\text { Healthcare services for my treatment have been provided according to just } \\
\text { and equitable principles }\end{array}$ & 64 & 95.3 & 6 & 3.5 & 2 & 1.2 \\
\hline $\begin{array}{l}\text { Healthcare professionals have responded to me and my relatives graciously, } \\
\text { respectfully and thoughtfully }\end{array}$ & 76 & 3.6 & 7 & 3.7 & 5 & 2.7 \\
\hline $\begin{array}{l}\text { I have been informed of my health condition, the medical procedure to be } \\
\text { applied, and the course of the disease or condition and its results }\end{array}$ & 80 & 45.5 & 77 & 43.8 & 19 & 10.8 \\
\hline $\begin{array}{l}\text { I know that my permission must be obtained for any treatment pertaining } \\
\text { to my condition or disease }\end{array}$ & 117 & 61.9 & 69 & 36.5 & 3 & 1.6 \\
\hline $\begin{array}{l}\text { I know that I have the right to reject or stop any treatment currently being } \\
\text { applied or planned }\end{array}$ & 80 & 45.5 & 77 & 43.8 & 19 & 10.8 \\
\hline $\begin{array}{l}\text { I know that I have the right to reject any reports or to demand a second } \\
\text { opinion pertaining to my condition or disease }\end{array}$ & 57 & 30.2 & 128 & 67.7 & 4 & 2.1 \\
\hline $\begin{array}{l}\text { I know that I have the right to complete confidentiality pertaining } \\
\text { to any consultation, diagnosis, treatment, or any other procedure related } \\
\text { to my condition or disease }\end{array}$ & 47 & 25.0 & 138 & 73.4 & 3 & 1.6 \\
\hline $\begin{array}{l}\text { I know that I will not be subjected to any clinical research without } \\
\text { my consent at any stage of my condition or disease }\end{array}$ & 41 & 21.7 & 148 & 78.3 & 0 & 0.0 \\
\hline
\end{tabular}


In the survey, $61.9 \%(\mathrm{n}=117)$ of the patients knew that their permission was required for any procedures related to their treatment for occupational diseases. Long-term patients knew of this requirement to a greater degree than short-term patients. In terms of the duration of hospital stays, there was a significant difference between those who were aware of this requirement and those who were not (Kruskal-Wallis Test, $\mathrm{p}=0.032$ ).

Other $51.8 \%(\mathrm{n}=86$ ) were not confident that they would recover from their diseases, with $36.1 \%(n=60)$ believing otherwise. Of these patients, $75.1 \%(n=142)$ affirmed that the conditions causing these diseases in their respective workplaces were pejorative, with no signs of improvement. When asked about their opinions on the possibilities of relapsing and whether they would return to work, 52.4\% ( $\mathrm{n}=99$ ) figured this could happen, but they would still return to the same job; $21.2 \%(\mathrm{n}=40)$ would quit; $20.6 \%$ $(\mathrm{n}=39)$ would return because of no other options; and $5.8 \%(\mathrm{n}=11)$ were undecided. It is worth noting that the education level may have influenced the answers provided by the respondents. Having been treated, the majority of secondary and higher school graduates prefer going back to the latest job. Among the primary school graduates, the percentages of "back to job" group and "quit" group are the same. Most of the surveyed participants who would return to the same job had in fact already gone back to workplaces that employed physicians (Pearson Chi-Square Test, $\mathrm{p}<0.05$ ). While most of the long-term hospitalized workers stated that they had no other option, most of the short-term hospitalized workers declared they would return to their same jobs (Kruskal-Wallis Test, $\mathrm{p}<0.05$ ).

\section{DISCUSSION}

Discussions on occupational medicine and its ethical and moral dilemmas are ongoing. These discussions focus on the protection and privacy of patient information; the responsibilities of employers as opposed to those of employees; the application of preventative measures at workplaces; the use of employees in experimental clinical studies; and recommendations and solutions [13-18]. According to Turkey's Labor Law, Article 81, employers are mandated to hire at least one workplace physician proportionately to the number of employees and compatibly with the emergency class and degree of labor at workplaces with a minimum of fifty workers [5,19]. There are estimated 11 million to 12 million people employed as industrial workers in Turkey [20]. Out of this number, approximately six million are currently insured [21]. Out of the employees on record, $58 \%$ of the laborers occupy jobs at workplaces where the number of employees is under fifty, and therefore they are deprived of workplace physicians assistance and employee healthcare services mandated by law for workplaces whose labor forces exceed fifty persons [22]. Our study concluded that employees treated in the hospital for occupational diseases were not adequately informed on the risks of these diseases. In our research, the hospitalized patients, especially those with lead poisoning, vocally expressed that they had either been poorly informed or never informed of the results of periodic evaluations. Documentation suggests that laboratory results of blood samples taken from employees in the occupational diseases hospital were not explained to the them for several months and that results from other laboratory facilities were in disagreement with the results provided by the hospital [23].

Our study also concluded that patients rights were expounded upon in hospitals, as evidenced by $93.6 \%$ of those surveyed who declared that healthcare professionals behaved politely and respectfully towards them. The attitudes of these healthcare professionals, their delicate approach to the patients, their kindness, attention and sensibility, all played an important role in comfort felt by the patients. Thanks to this, they were able to feel at ease with their healthcare providers, which increased the patients' cooperation with the treatment. Furthermore, the patients sufficiently expressed their trust in the treatments 
and in the nursing and healthcare teams providing the treatment [24].

As noted in the survey, healthcare professionals are legally and ethically obligated to give instructions to patients, without being asked to do so. Moreover, it is both necessary and appropriate to advise patients of the risks related to invasive diagnostic and therapeutic procedures, to obtain the patient's consent, and to document this information $[12,25]$. In our study, although the patients were mostly pleased with the attitudes of their healthcare providers, only half of these patients claimed to have been adequately informed on their conditions and treatments, which leads to the conclusion that physicians had been negligible in following new legal procedures, especially those enacted under the Turkey's Penal Code mandating that precise information be given to patients - a current issue in malpractice lawsuits.

Our study documented that slightly over half of the patients in the occupational diseases hospital were cognizant that patient permission had to be obtained beforehand for all medical procedures and that patients had the right to reject any and all treatment offered. Informing patients about any treatment and obtaining their consent before applying that treatment is a prerequisite and a sign of respecting individual personalities and freedom [26-31]. In our research, the fact that slightly over half of those surveyed were not even aware of their rights necessitates that patients must be more informed. In another research, the approval rate of treatment for patients hospitalized in a university hospital was even lower than the rate in our study, which was $44 \%$ [32].

The present survey concluded that most patients were not aware of their right to reject medical evaluations or to demand a second opinion from other institutions. However, one of the rights defined by Turkish law is the right to demand corrections in medical records.

With regard to ethics, confidentiality is a crucial element that should be applied to all medical procedures. Additionally, the Regulation of Patients Rights has put forth the rule that all medical procedures must be kept confidential in order to respect the privacy of patients [14]. Nonetheless, this study determined that only $25 \%$ of those surveyed had any notion of this right. In his pilot research on the patients' views, Jones stated that while all participants expected their physicians to protect their privacy, only $72 \%$ declared that this was actually the case [33]. Moreover, 78.3\% of the participants in our study had no information on their rights, for example, their right to decide whether they want to participate in experimental clinical studies, or their right to disclose their medical records. Perhaps this finding was obtained due to the fact that the hospital in which the survey took place is more a treatment facility, with few clinical studies conducted there.

Longer hospital stays were directly related to the amount of information the patients received. At the hospital included in the research, information on patients rights was intermittently given to patients by a member of the nursing staff as brochures were distributed. Our study recommends that providing this information to every inpatient would be far more beneficial. In the survey conducted by Ozturk et al. the participants stated that notification of patient rights was generally neglected [34]. In the research conducted by Tasdemir et al. most of the patients had no cognizance of patient rights [35]. Compatible with these two studies, the results of our research also indicated that notification of patients' rights was insufficient and ineffective at this particular hospital of occupational diseases.

Although the patients in this survey were hospitalized due to curable diseases, their hopes of complete recovery might have been influenced by assuming that the conditions leading to their diseases could not be improved at their workplaces. Those employed at workplaces with physicians believed that greater healthcare had been provided for them; therefore, they displayed more determination to return to the same jobs. These patients also declared that they would return to their workplaces, even though the health conditions had not improved, because finding 
another job would be too difficult and would induce financial stress; otherwise, there was no other solution.

In contrast to long-term patients, workers hospitalized for short stays believed they had suffered less injury from their occupational diseases and wanted to return to their jobs. Workers hospitalized for longer stays stated that they wanted to return to the same jobs because they had no other option. These employees stated that after witnessing unhealthy conditions in their work environments and observing workers with occupational diseases, they had realized the dangers. However, less than satisfactory education level and the risk of unemployment kept them from leaving their jobs.

\section{CONCLUSION}

Furthermore, this study concludes that preventive healthcare at workplaces and therapeutic healthcare at the occupational diseases hospital are both introduced equitably as mandated.

Since the inpatients at the hospital of occupational diseases had not been sufficiently informed of their patient rights, they were unaware of their right to reject treatments; to object to evaluation of their health conditions; to demand second opinions from other institutions; to demand confidentiality; or to choose not to participate in experimental clinical studies.

In Turkey, we are of the opinion that further competency and control should be put into force to provide more sufficient employee healthcare and to establish ample environments for workplace physicians to perform their responsibilities autonomously. These recommendations, if enacted upon, will enhance occupational safety and provide greater prevention and diagnosis of occupational diseases.

\section{ACKNOWLEDGEMENTS}

We wish to thank Robert Jester for his contribution to review the translation.

\section{REFERENCES}

1. Bilir N. General Principles of the Occupational Diseases. In: Bilir N, Ylldı AN, editors. The Labour Health and Security. Ankara: Hacettepe University Publications; 2004. p. 135-52 [in Turkish].

2. Social Insurance Law. No. 506. Approval Date: 17/07/1964. Date of Publication in the Official Gazette: 29, 30, 1964/07/311964/08/01:11766-79 [in Turkish].

3. The social security health procedures by-law. No. 506. Approval Date: 17/07/1964. Date of Publication in the Official Gazette: 1972/6/22. Issue 14223 [in Turkish].

4. The Law of General Public Health. No. 1593. Approval Date: 1930/4/24. Date of Publication in the Official Gazette: 1930/5/6. Issue: 1489 [in Turkish].

5. The Labour Law. No. 4857. Approval Date: 2003/5/22. Date of Publication in the Official Gazette: 2003/6/10. Issue: 2513. [in Turkish].

6. The Ministry of Labour and Social Security. The Statutes of the Workplace Health Units and the Missions of the Workplace Physicians and the Labour Methods and Principles. Date of Publication in the Official Gazette: 2003/12/16. Issue: 25318 [in Turkish].

7. Medical Expertise Charter. Date of Publication in the Official Gazette: 2002/6/19. Issue: 24790 [in Turkish].

8. Fisek G. The Employee Health and its Extents. Ankara: Turkish Medical Union; 1993. p. 7-10 [in Turkish].

9. Directorate General of Occupational Health and Safety, Ministry of Labour and Social Security. Upgrading Occupational Health and Safety in Turkey [cited 2009 Jan 10]. Available from URL: http:/www.icohweb.org/core_docs/ code_ethics_tur.pdf. [in Turkish].

10. Westerholm P. Professional ethics in occupational health-West European perspectives. Ind Health 2007;45:19-25.

11. London L. Dual Loyalties and the Ethical and Human Rights Obligations of Occupational Health Professionals. Am J Ind Med 2005;47:322-32. 
12. Palmer KT, Harling CC, Harrison J, Macdonald EB, Snashall DC. Good Medical Practice: Guidance for Occupational Physicians. Occup Med 2002;52:341-52.

13. Tabershaw IR. Conference on Ethical Issues in Occupational Medicine. Bull NY Acad Med 1978;54:810-7.

14. Brandt-Rauf PW. Ethical Conflict in the Practice of Occupational Medicine. Br J Ind Med 1989;46:63-6.

15. Matimo KP, Antti-Poika M, Leino T, Rossi K. Ethical Issues Among Finnish Occupational Physicians and Nurses. Occup Med 1998;48:375-80.

16. Lurie SG. Ethical Dilemmas and Professional Roles in Occupational Medicine. Soc Sci Med 1994;38:1367-74.

17. Aw TC. Ethical Issues in Occupational Medicine Practice: Knowledge and Attitudes of Occupational Physicians. Occup Med 1997;47:371-6.

18. London L, Kisting S. Ethical Concerns in International Occupational Health and Safety. Occup Med 2002;17:587-600.

19. Suzek S. Employee Health and Labour Security from the Judicial Aspect. In: The Lecture Notes of Labour Medicine. Ankara: Turkish Medical Union, 1993. p. 21-51 [in Turkish].

20. Employee health, occupational accidents and occupational diseases in our country. Izmir Tabip Odasi [cited 2008 Jul 25]. Available from URL: http:/2009.izmirtabip.org.tr/images/ docs/mhast.pdf [in Turkish].

21. The number of insured employees increased 9.4\% [cited 2009 March 19]. Sabah 2006 Sept 29; Economi. Available from URL: http://arsiv.sabah.com.tr/2006/09/27/ ek097.html [in Turkish].

22. Fisek AG. Health Security in Work Life. Ankara: Fisek Institute for Working Children Foundation of Science and Activity Center; 2009 [in Turkish].

23. Bakır O. Lead workers in accumulator factories. Turk J Occup Health Saf 2007;30:16-9 [in Turkish].
24. Ozcan M, Ozkaynak V, Toktas I. The levels of satisfaction of applicants to Silvan Public Hospital. Dicle Med J 2008;35: 96-101 [in Turkish].

25. Turkish Penal Code [Turk Ceza Yasasi]. No. 5237. Approval Date: 2004/09/26. Date of Publication in the Official Gazette: 2004/10/12. Issue: 25611.

26. Kihlbom U. Autonomy and negatively informed consent. J Med Ethics 2008; 34: 146-9.

27. Worthington R. Clinical issues on consent: Some philosophical concerns. J Med Ethics 2002;28:377-80.

28. O'Neill O. Paternalism and Partial Autonomy. J Med Ethics 1984;10:173-8.

29. Tripp JH. Commentary. 1: The Right to Refuse Treatment. J Med Ethics 1997;23:159.

30. Bhangu A, Hood E, Datta A, Mangaleshkar S. Is informed consent effective in trauma patients? J Med Ethics 2008;34:780-2.

31. Hansson MO. Balancing the Quality of Consent. J Med Ethics 1998;24:182-7.

32. Donmez L, Culbant AB, Yuce A, Taskin T. The situation of the utilization of some patient rights by persons who are over age 15 and who live in the region of Kutukcu Cottage Hospital Numbered 6 and their opinions of the behaviours of personnel serving at different health foundations. Tip Etiği 2001;9:42-48 [in Turkish]. 33. Jones C. The utilitarian argument for medical confidentiality: A pilot study of patients' views. J Med Ethics 2003;29:348-52. 34. Ozturk H, Yllmaz F, Hindistan S, Cilingir D, Yesilcicek K. The evaluation by a physician, a nurse, and patients on patient rights applied at the hospital. Tip Etiği 2007;15:145-52 [in Turkish].

35. Tasdemir M, Ehliz H. The evaluation of the knowledge, attitudes, and behaviors on patients rights of patients hospitalized at public hospitals in. In: Göktürk E, Şahin A, Odacioğlu Y, editors. The Book of the 5th International Symposium of Health Foundations and Hospital Management5. Eskișehir: Osmangazi University Press; 2002 [in Turkish].

This work is available in Open Access model and licensed under a Creative Commons Attribution-NonCommercial 3.0 Poland License - http://creativecommons.org/ licenses/by-nc/3.0/pl/deed.en. 